\title{
Nature's Fire Wardens
}

\author{
CHARLIE ABRD, USHERVILLE
}

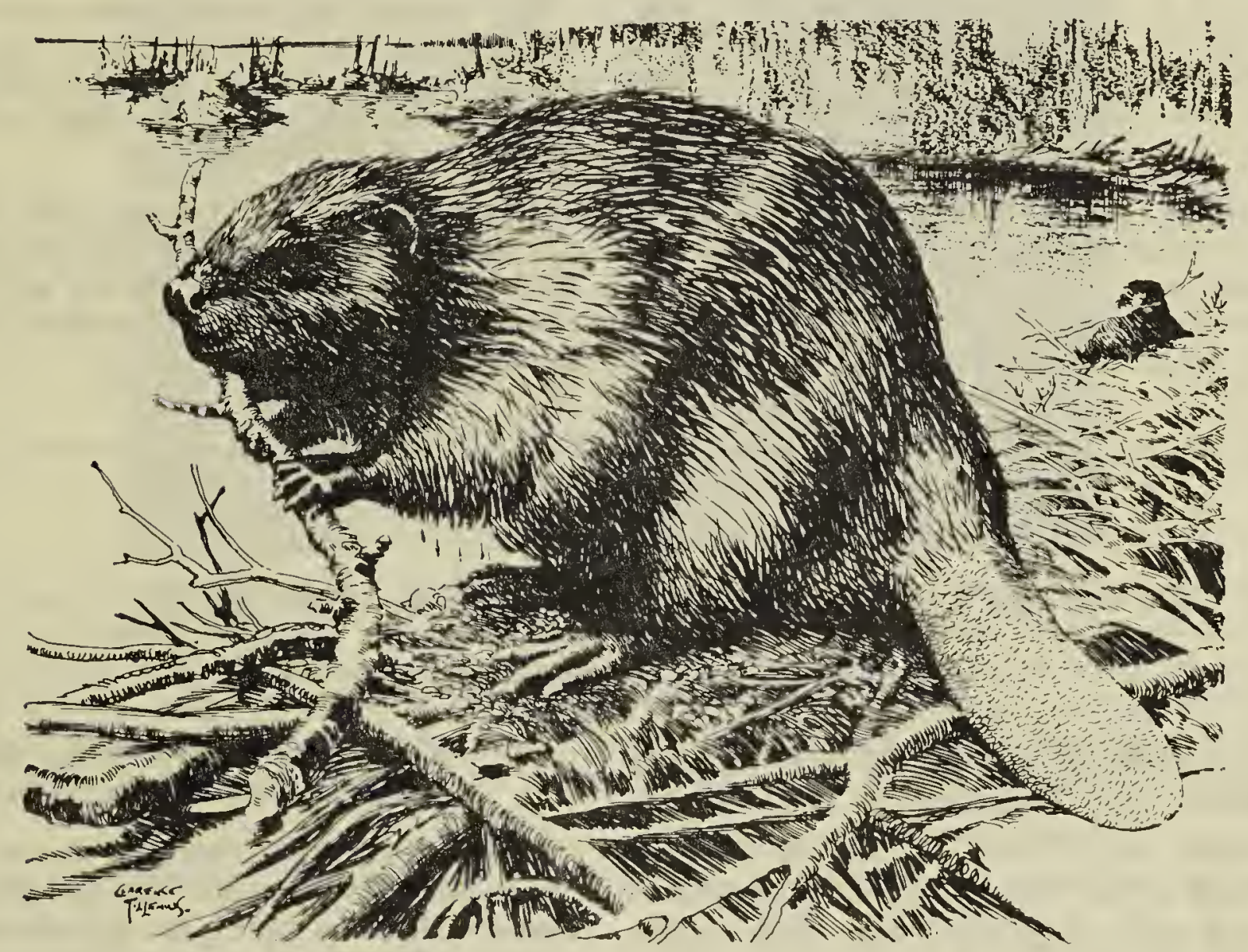

To picture what the northern forests were like when the beaver flourished almost unmolested, we will have to depend to some extent on our imagination. However, the evidence was left to show and it is not hard to piece together.

Every creek, large or small, and every water runway through the forests were inhabited by beavers. Great chains of dams would crisscross through the forests in every direction, holding back the water, and all wild life would be in abundance. Great stands of timber grew up and remained through the centuries. Fires must have started in those years, as fires will start from natural causes-such as lightning-but at that time they could only burn over small areas. They would be cut off in every direction by water. Nature's Fire Wardens were on the job.

Then came the fur posts and the trappers. The destruction of the beaver must have taken several years but it was very thorough. Almost to the last beaver they became -Just Beaver Pelts.

The dams washed out. The water ran off to the rivers and away to the sea. The great stands of timber remained, yes, but they were now vulnerable to fires-Nature's Fire Wardens had departed.

For the next picture I do not need to use my imagination. I was eyewitness to part of it. There came a period of dry years and fires broke out in the timber. Men were now the fire wardens. ' Fire-fighting crews were organized and moved in to extinguish them. Imagine, if you can, trying to fight fire when, in extreme cases, there was no water within miles -not even to drink. The long chains of what were beaver ponds were now long chains of rank dry grass to spread the fire far into the timber. The decaying beaver dams went to deep ground fires. Men fought hard to save the forests but too often it 
was a losing battle-too often the great fires triumphed over men's best efforts. Every dry season large stands of timber went up in smoke, and with it went the wild life.

A few years ago a project was started to reinstate the beaver in the northern forests. From scattered colonies that were left, such as in the Cypress Hills, they were brought, a few at a time and liberated at various suitable locations throughout the northern bush country. These soon multiplied and began to move up the creeks and rebuilt the old dams. The re-stocking continued from any outside source available.
This project has been successful. The beaver are getting back on the job again and are rebuilding their chains of waterways through the forests. In their wake are coming the muskrats and other wild life.

Dry years will come again and fires will break out, but this time the fire rangers will have a co-operative assistant to aid them in their efforts to "Save the Forests."

I would add that beaver are, not as a rule, desirable in settled country as they will flood grain fields and hay meadows. The beavers are at home in the forests.

\section{Further Aims of the Society}

DR. GEORGE LEDINGHAM, REGINA

The Saskatchewan Natural History Society was founded in 1949 to encourage an interest in, and an understanding of, nature. The immediate aim was to help with the publication of the "Blue Jay" which had been the inspiration and responsibility of the Yorkton Natural History Society. There were several years both before and after S.N.H.S. was formed when the "Blue Jay" survived only because of the active help and co-operation of the Provincial Museum.

Perhaps the "Blue Jay" is now sufficiently successful so that we may think of the other aims of the Society. These are stated as follows in our constitution:

(1) encouraging the foundation of local natural history societies;

(2) helping and co-operating with our provincial museum;

(3) developing projects to stimulate interest in nature among young people, and

(4) studying means by which we (as individuals and as a soci- ety) may contribute toward conservation of our wild life.

The first step toward these aims was taken when Mr. J. L. Buckley moved that a brief be prepared for presentation to the Royal Commission of Agriculture and Rural Life. A committee prepared the general statement which you saw in the last issue of the "Blue Jay." A few thoughtprovoking letters came in and a brief will be submitted on July 1. May I take this opportunity to thank those who took time in the busy spring season to send in their thoughts and may I remind others that letters will still be welcomed by the committee. The brief will give some of our thoughts on the important problems of natural history in Saskatchewan. There will be a chance when our brief is reviewed by the commission to add other ideas. Perhaps some of you may be free to attend the hearings in October or November and will help us, at that time, to express the thoughts and feelings of Natural History Society members.

If you think our aims are good, or if you know of specific things which we should do, write and tell us. The strength of our brief will be proportional to the response from our members. 